\title{
Correction to: Atherothrombosis Prevention and Treatment with Anti-interleukin-1 Agents
}

\author{
Giuseppe Biondi-Zoccai ${ }^{1,2}$. Cristian M. Garmendia ${ }^{3}$ - Antonio Abbate ${ }^{3}$ - Arturo Giordano $^{4}$ - Giacomo Frati ${ }^{1,5}$. \\ Sebastiano Sciarretta ${ }^{1,5} \cdot$ Barbara Antonazzo $^{6}$. Francesco Versaci ${ }^{7}$
}

Published online: 29 January 2020

(C) Springer Science+Business Media, LLC, part of Springer Nature 2020

Correction to: Current Atherosclerosis Reports (2020) 22:4

https://doi.org/10.1007/s11883-020-0819-1

The original version of this article unfortunately contained typo in the 2nd author's family name. Instead of "Garmenda", it should be "Garmendia". The original version has been corrected.

The online version of the original article can be found at https://doi.org/ 10.1007/s11883-020-0819-1

Giuseppe Biondi-Zoccai

giuseppe.biondizoccai@uniroma1.it

1 Department of Medico-Surgical Sciences and Biotechnologies, Sapienza University of Rome, Corso della Repubblica 79, 04100 Latina, Italy

2 Mediterranea Cardiocentro, Naples, Italy

3 Pauley Heart Center, Department of Internal Medicine, Virginia Commonwealth University, Richmond, VA, USA

4 Unità Operativa di Interventistica Cardiovascolare, Presidio Ospedaliero Pineta Grande, Castel Volturno, Italy

5 IRCCS NEUROMED, Pozzilli, Italy

6 Division of Geriatrics, Israelite Hospital, Rome, Italy

7 Unità Operativa Complessa di Cardiologia, Ospedale Santa Maria Goretti, Latina, Italy 